\title{
Study of Interaction Between Bovine Serum Albumin and Dolutegravir Intermediate: Fluorescence and Molecular Docking Analysis
}

\author{
Sunita Behera ${ }^{1}$, Rubi Behura ${ }^{1}$, Patitapaban Mohanty ${ }^{1}$, Mitali Sahoo ${ }^{1}$, Ramakrishna Duggirala \\ Subrahmanya ${ }^{1}$, Anil Kumar Verma ${ }^{2}$, Bigyan Ranjan Jali 1,*(D) \\ 1 Department of Chemistry, Veer Surendra Sai University of Technology, Burla Sambalpur-768018, Odisha, India \\ 2 Department of Microbiology, Sikkim University, Gangtok, 737102, India \\ * Correspondence: bigyan.Jali7@gmail.com;
}

Scopus Author ID 36503969200

Received: 4.01.2021; Revised: 30.01.2021; Accepted: 1.02.2021; Published: 7.02.2021

\begin{abstract}
Novel (4R,12aS)-7-methoxy-4-methyl-6,8-dioxo-3,4,6,8,12,12a-hexahydro-2H-pyrido[1',2':-4,5]-pyrazino[2,1-b][1,3]oxazine-9-carboxylic acid (L) was synthesized and characterised. The interaction between bovine serum albumin (BSA) with L was scrutinized by steady-state fluorescence spectroscopy, fluorescence anisotropy, fluorescence lifetime, and molecular docking methods. The fluorescence titration experiments of BSA resulted in fluorescence quenching with the incremental addition of $\mathrm{L}$. The conformational binding of $\mathrm{L}$ to BSA has been investigated by molecular docking analysis. The molecular probe's best conformation showed the affinity as free binding energy release of $-7.93 \mathrm{Kcal} / \mathrm{mol}$. The docking analysis confirms that ligand binds in the near vicinity of TRP-213 in the binding pocket of subdomain IIA.
\end{abstract}

Keywords fluorescence; anisotropy; lifetime; docking analysis; receptor.

(C) 2021 by the authors. This article is an open-access article distributed under the terms and conditions of the Creative Commons Attribution (CC BY) license (https://creativecommons.org/licenses/by/4.0/).

\section{Introduction}

The study of protein-ligand interactions has played an incredible role in its industrial, biological, cosmetics, and pharmaceutical applications. Serum albumins are the most abundant protein in plasma [1-5]. Its remarkable acceptor capabilities with various active molecules are a dynamic tool in developing novel therapeutic agents, the prognosis of the pharmacokinetic behavior of drugs, and pharmacodynamics modulations [6-10]. BSA acts as a kind of serum albumins, which has been used as a model protein for various studies. BSA is a large globular protein. Its molecular weight is $66000 \mathrm{Da}$ [11-14]. It is constituted by 582 amino acid residues. It also comprises 17 disulfide bridges and a free -SH groups. It is made up of three distinct homologous domains I, II, and III; each homologous domain is divided into two subdomains A and B. It embraces two tryptophan residues, namely, Trp-213 and Trp-134. It is well known that the Trp-134 is located in a hydrophilic environment close to the protein surface (subdomain-I B). However, Trp-213 is located in the largest hydrophobic cavity, domain II (subdomain-II A). The major binding sites of BSA are situated in subdomains IIA and IIIA [1523]. For protein-ligand interactions, site maker fluorescence molecular probes are utilized. The interactions between BSA with ligands led to important information about the absorption and distribution of the drug. The fluorescent emission plays an important role in protein-ligand interactions due to their high selectivity, excellent sensitivity, and quick response abilities. The 
fluorescence emission can provide essential information about the binding mechanism, binding mode, binding constants, and site [24-28].

\section{Materials and Methods}

\subsection{Materials.}

BSA and spectroscopic grade solvent were obtained from Sigma, USA, and Merch, India and used. The ${ }^{1} \mathrm{H}-\mathrm{NMR}$ spectra were recorded on Varian-AS 400 spectrometers. The fluorescence spectra were obtained by using a Perkin-Elmer LS-55 spectrofluorimeter. The derivative (L) [29] by reported literature is shown in Figure 1. A $10 \mathrm{mM}$ phosphate buffer $\mathrm{pH}$ 7 was prepared to prepare protein solution and fluorescence titration experiments.

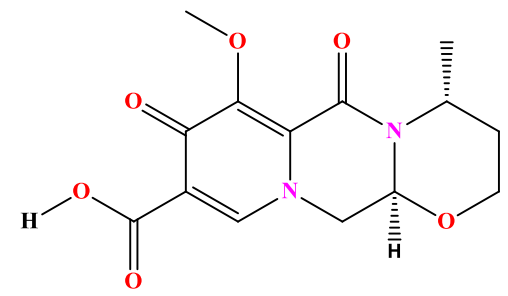

Figure 1. (4R,12aS)-7-methoxy-4-methyl-6,8-dioxo-3,4,6,8,12,12a-hexahydro-2H-pyrido-[1',2':4,5]pyrazino[2,1-b][1,3]oxazine-9-carboxylic acid (L).

\subsection{Protein sequence and ligand preparation.}

Bovine Serum Albumin (BSA) protein sequence was retrieved from the Protein Data Bank (PDB id: 4f5s). The file opened in Discovery Studio Visualiser where Hetatoms and chain B were removed and the protein file saved in pdb format. The $\mathrm{L}$ was built in the Chemdraw (Chemoffice-17). The $\mathrm{L}$ was opened in Chem3D and subjected to energy minimized using the force field MMFF94 with a maximum number of iteration 500 and a minimum RMS gradient of 0.1 . The energy-minimized structures were saved in $\mathrm{pdb}$ format for further use for docking purposes.

\subsection{Molecular docking study.}

The docking study was performed using Autodock 4.2.5. Auto dock predicts the bound conformations of flexible ligands to bio macromolecular targets using the Lamarckian genetic algorithm. It was done according to the literature report [30-31]. In brief, the PDBQT files were generated for protein and ligands molecules by adding polar hydrogen and Kollman charges in the case of the macromolecule, whereas in molecular probes, non-polar bonds are merged, and Gasteiger charges were applied. The grid box dimension was fixed to 74,68,66 ( $x, y, z$ coordinates) with default $0.375 \AA$ grid point spacing. For docking simulation and conformational search, Lamarckian Genetic Algorithm (LGA) was chosen Moreover, the number of the evaluation were set to be 20 and rest other parameters were kept default. The molecular docking result was evaluated in PyMOL (The PyMOL Molecular System, Version 2.0 Schrodinger, LLC, and Discovery Studio Visualiser.

\subsection{Binding constant calculation equation.}

Binding constants of BSA and HSA with substrates were determined using the BenesiHildebrand equation by the fluorescence method in Eq. 1. 


$$
1 / \Delta \mathrm{F}=1 / \Delta \mathrm{Fmax}+(1 / \mathrm{Ka}[\mathrm{C}] \mathrm{n}) \times(1 / \Delta \mathrm{Fmax})
$$

Here $\Delta \mathrm{F}=\left(\mathrm{F}_{\mathrm{x}}-\mathrm{F}_{0}\right)$ and $\Delta \mathrm{F}_{\max }=\mathrm{F}_{\infty}-\mathrm{F}_{0}$, where $\mathrm{F}_{0}, \mathrm{~F}_{\mathrm{x}}$, and $\mathrm{F}_{\infty}$ are the emission intensities of BSA in the absence of substrate, at an intermediate substrate concentration, and at a concentration of the complete interaction, respectively. $\mathrm{K}_{\mathrm{a}}$ is the binding constant, $\mathrm{C}$ is the concentration of the substrate, and $\mathrm{n}$ is the number of substrate-bound each to BSA (here $\mathrm{n}=$ $1)$.

\section{Results and Discussion}

The derivative (L) was prepared based on the literature report [29]. Fluorescence titration experiments show the interaction between proteins and ligands. BSA comprises three fluorophores, tryptophan, tyrosine, and phenylalanine [30-33]. Due to the low quantum yield of phenylalanine and almost quenched tyrosine features, the intrinsic fluorescence occurred mainly due to tryptophan residues. The interaction between proteins with various molecular probes can be diminished the fluorescence intensity of protein, which is known as fluorescence quenching. The fluorescence quenching mechanism can be dynamic, static; the static and dynamic quenching is simultaneously involved. Dynamic quenching ascribes from interaction through the collision between the fluorophores and quencher [34-35]. However, static quenching results from the formation of a complex between the fluorophores and quencher [36]. Fluorescence quenching of the protein provides important evidence about the molecular microenvironment modifications in the chromophore molecules' vicinity and the proteinligands interactions. [37-40].

BSA shows a strong emission band at $344 \mathrm{~nm}$ upon excitation at $295 \mathrm{~nm}$. The peak at $344 \mathrm{~nm}$ is occurred due to the presence of tryptophan residue in the protein. The sequential addition of ligand to BSA shows the decreased fluorescence emission with increasing the concentration of ligand. It indicates the binding of the ligand with BSA. Upon addition of ligand to BSA, fluorescence emission quenched along with a redshift (13 nm) of emission band from 344 to $357 \mathrm{~nm}$ indicates the ligand's binding to BSA shown in Figure 2a. The literature found that fluorescence emission shifted from lower to higher wavelengths upon protein unfolding [41-42]. The equilibrium association constant $\left(\mathrm{Ka}, 6.80 \times 10^{4} \mathrm{M}^{-1}\right)$ determined from the plot shown in Figure 2b. is presented in Table 1.
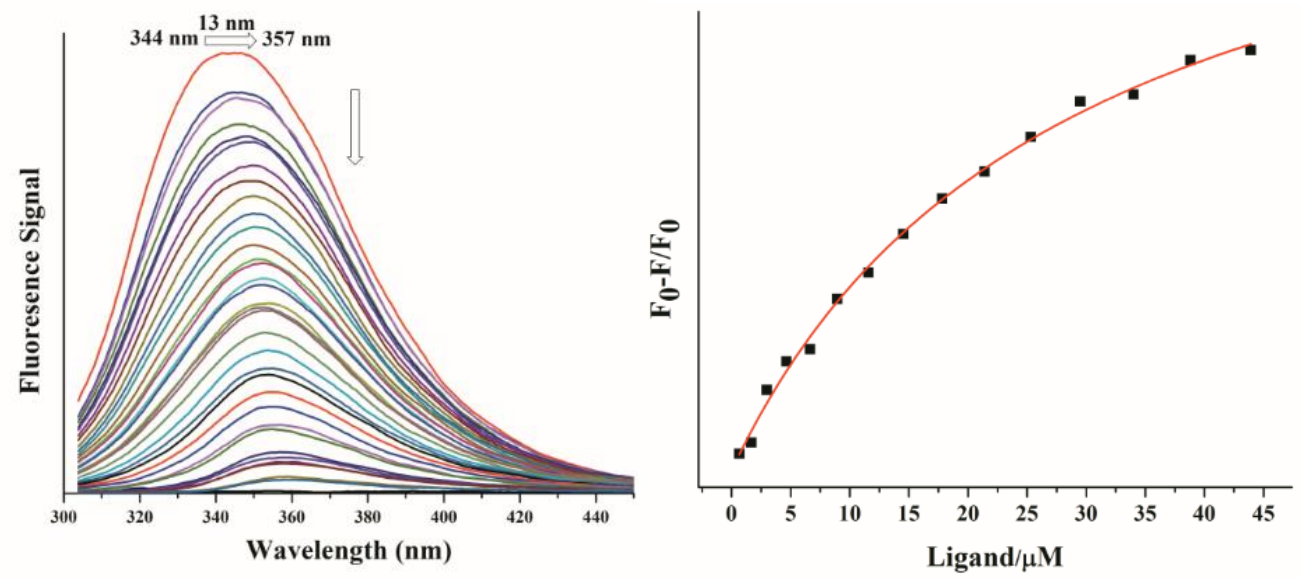

Figure 2. Fluorescence spectra of $6 \mu \mathrm{M}(3 \mathrm{~mL}) \mathrm{BSA}$ in the presence of (a) molecular probe L; with increasing concentrations in the range of 0 to $48 \mu \mathrm{M}$ (phosphate buffer, $\mathrm{pH} 7$ ); (b) Binding constant plots of L with BSA.

Solid lines indicate the fit using the Hill equation. 
To gain the more information regarding protein- ligand interaction, it has been performed steady-state fluorescence anisotropy of BSA in the absence or the presence of the compounds by using equation 2. The increase in anisotropy values of BSA in the presence of compounds support their binding properties. From these values, it is clear that BSA's initial symmetric state with anisotropy value close to zero [43] changed upon interactions with L. The higher anisotropy values indicated their ability to change the shape of the BSA protein. This is also in agreement with the observed order of the binding constants.

$$
\mathrm{r}=(\mathrm{Ivv}-\mathrm{GIvH} / \mathrm{Ivv}+2 \mathrm{GIvH})
$$

Table 1. Binding constant and Anisotropy of BSA with L.

\begin{tabular}{c|c|c} 
Sample $^{\mathbf{a}}$ & $\mathbf{K}_{\mathbf{a}}\left[\mathbf{M}^{-\mathbf{1}}\right] \times \mathbf{1 0}^{\mathbf{4}}$ & ${\text { Anisotropy of } \mathbf{B S A}^{\mathbf{b}}}^{\mathbf{b}}$ \\
\hline BSA+ L & 6.80 & 0.116 \\
\hline \multicolumn{2}{c}{ Note: $\mathrm{a}=2 \mu \mathrm{M}\left(\begin{array}{c}\text { ( } \mathrm{mL}) \text { BSA in } 20 \mathrm{mM} \text { in phosphate buffer, } \mathrm{pH} 7 . \\
\mathrm{b}=\text { Anisotropy of BSA }=0.082\end{array}\right.$}
\end{tabular}

\subsection{Molecular docking result.}

BSA contains three homologous domains I, II, and III. Each homologous domain is divided into two subdomains, $\mathrm{A}$ and $\mathrm{B}$. The molecular docking analysis can be used to retrieve information about the protein-ligand interactions [44]. The interaction between protein-ligands occurred mainly in subdomains IIA and IIIA. The literature envisaged that the molecular probes or drugs bind at site IIA or IIIA [45-46]. To gather more information about proteinligand interactions, we have performed molecular docking analysis. The docking calculations are depicted in Table 2. Figure 3a shows that the molecular probe bind in subdomain IIA near the TRP-213 residue. The hydrogen bond architecture between the molecular probes and amino acid residues plays a tremendous role in stabilizing protein-ligand interactions. Besides that, $\mathrm{L}$ is enclosed by several hydrophobic and polar moieties. Hydrophobic interactions and charged and polar residues also provided extra stability of protein-ligand interactions through various amino acid residues such as ASP-450, SER-453, LEU-454, ARG-194, LEU-197, ARG-198, SER-201, LEU-210, LEU-480, LEU-346, VAL-342, SER-0343, and ALA-341. From these observations, it was demonstrated that ligand was bound with BSA.

Table 2. Key amino acids displayed polar interaction and hydrophobic interaction (underline) on docking.

\begin{tabular}{|c|c|c|c|}
\hline Ligand & $\begin{array}{c}\text { Predicted free energy of } \\
\text { binding by docking, } \\
\Delta G, \text { Kcal/mol }\end{array}$ & Polar interactions & Residue within 4 Å region \\
\hline $\mathbf{L}$ & -7.93 & ARG-217 & $\begin{array}{l}\text { ASP-450, SER-453, LEU- } \\
\text { 454, ARG-194, LEU-197, } \\
\text { ARG-198, SER-201, } \\
\text { LEU210, LEU480, } \\
\text { TRP213, LEU-346, VAL- } \\
\text { 342, SER343, } \underline{\text { ALA-341, }}\end{array}$ \\
\hline
\end{tabular}

Zhang and his coworkers reported that increased protein-ligand complex stability is due to the increased hydrophobicity nature in his pioneer work. The formation of hydrogen bond architecture between protein and ligand diminished the hydrophilicity characteristics and helped increases hydrophobicity, which stabilizes the protein-ligand interaction [47]. The best conformation of ligand molecules showed the affinity as free binding energy release of -7.93 $\mathrm{Kcal} / \mathrm{mol}$. It is due to the spontaneous complexation reaction. The docking analysis confirms that ligand binds in the near vicinity of TRP-213 in the binding pocket of the site I. 


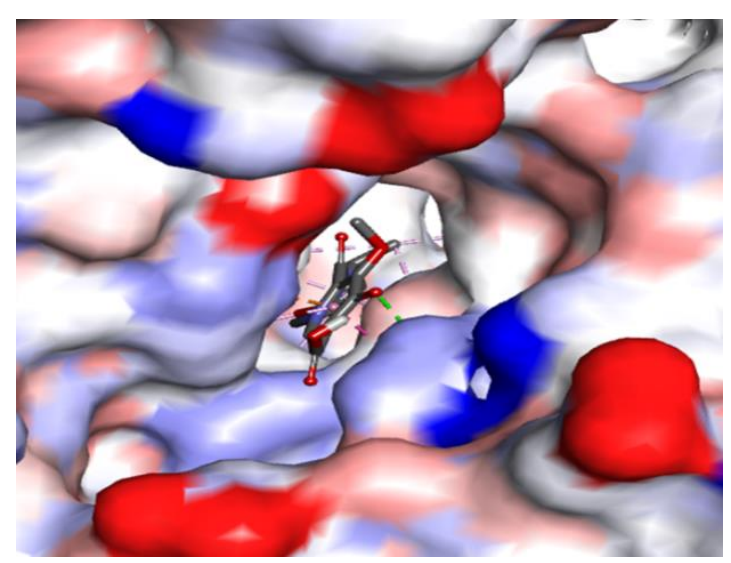

(a)

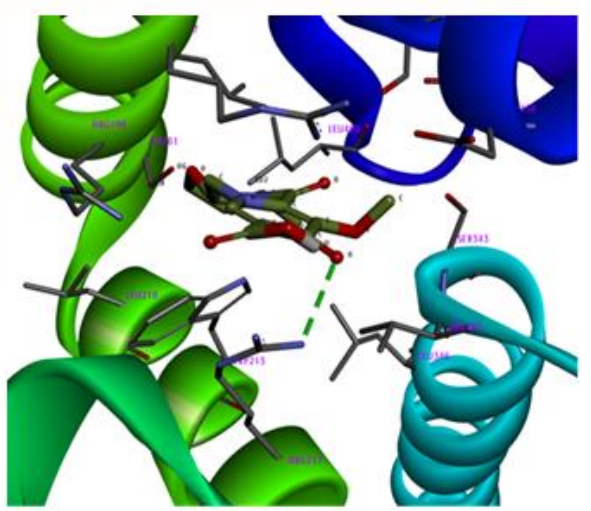

(c)

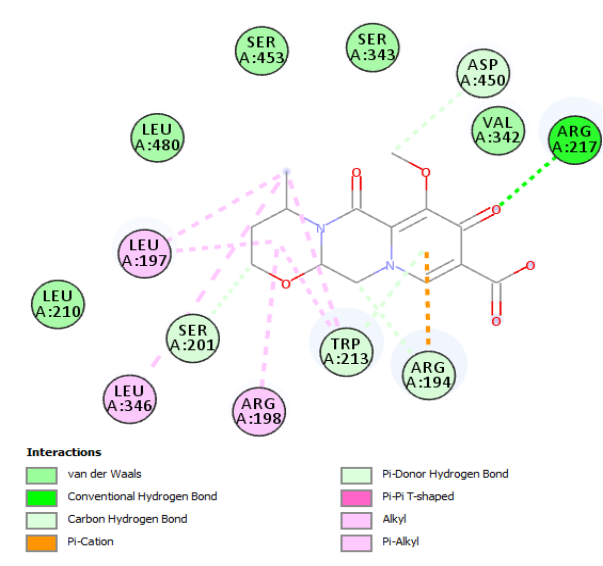

(b)

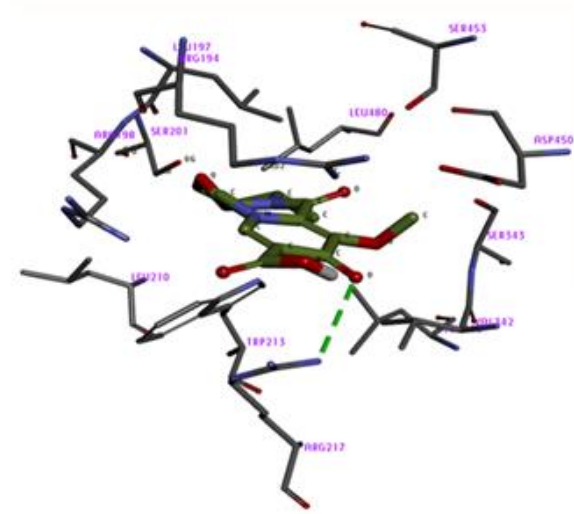

(d)

Figure 3. (a) Surface view of macromolecule BSA displaying the cavity where ligand goes and interact with nearby amino acids. The figure was generated using the python molecular viewer program; (b) 2D depiction of

ligand-binding residues showing interactions with different color codes. The figure was generated using Discovery Studio 2017 R2 program (https://www.3dsbiovia.com); (c) Ribbon representation of macromolecule BSA interacting with ligand L; (d) Key amino acid residues of BSA within the $4 \AA$ region of docked ligand showing the overall orientation and interaction in stick view. Both the figures were generated using Discovery Studio 2020 Client program (https://www.3dsbiovia.com).

\subsection{Fluorescence lifetime study.}

The fluorescence lifetime decays were studied for BSA with ligand (Table 3). Depending on the conditions, native BSA showed three [48-51] or two lifetimes [52-54]. It has been observed that three lifetimes for BSA as the best-fit decay profile is obtained from three exponential rather than the two exponential functions. At the same time, the interactions of the ligand with BSA changes these lifetimes significantly.

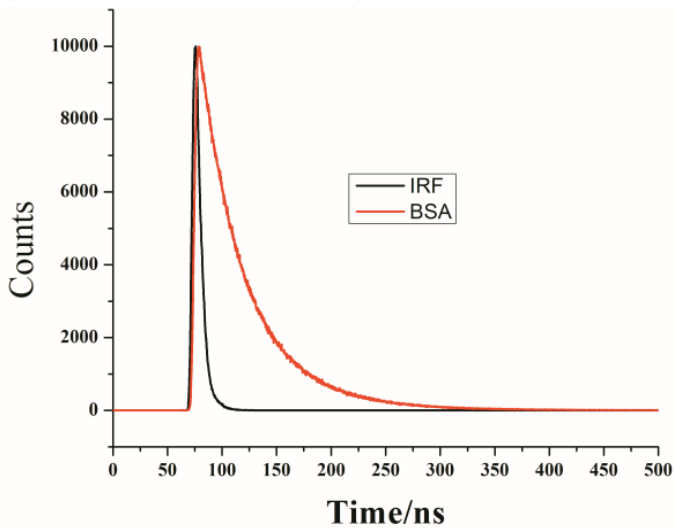

(a)

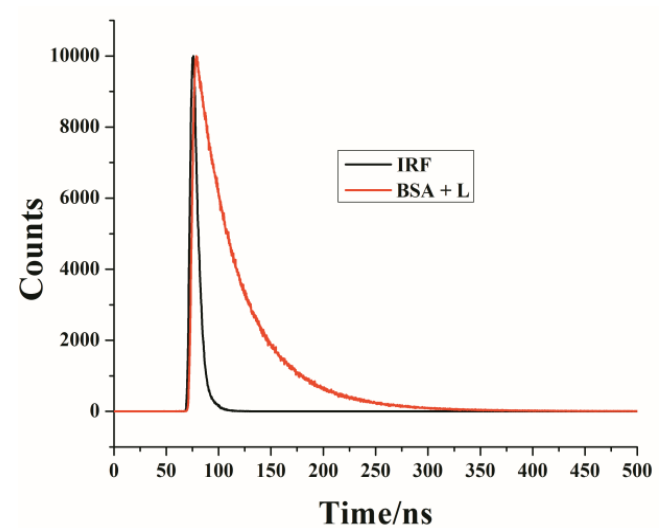

(b)

Figure 4. Fluorescence lifetime decay of (a) BSA; (b) BSA with L. 
The drastic change in the lifetime suggests the strong interactions by the tryptophan residue in the BSA, as shown in Figure $4 \mathrm{~b}$. This occurs as this lifetime is characteristic of a free tryptophan [55-60]. Upon addition of ligand to BSA, the lifetime changes drastically, and values are listed in Table-3.

Table 3. Fluorescence lifetime of BSA with $\mathbf{L}$

\begin{tabular}{|c|c|c|c|c|c|}
\hline Samples & $\lambda_{\mathrm{em}}(\mathrm{nm})$ & $\tau^{1}(\mathrm{~ns}) /(\mathbf{f}) \%$ & $\tau^{2}(\mathrm{~ns}) /(\mathbf{f}) \%$ & $\tau^{3}(\mathrm{~ns}) /(\mathbf{f}) \%$ & $\chi^{2}$ \\
\hline BSA & \multirow{2}{*}{344} & $0.449(2.63)$ & $3.762(35.24)$ & $7.327(62.13)$ & 1.06 \\
\hline $\mathbf{B S A}+\mathbf{L}$ & & $4.214(28.26)$ & $7.241(35.92)$ & $1.118(35.82)$ & 1.14 \\
\hline
\end{tabular}

\section{Conclusions}

In this present study, the interaction between the synthesized derivatives with BSA was investigated using steady-state fluorescence, fluorescence anisotropy, fluorescence lifetime, and molecular docking analysis under physiological condition $\mathrm{pH}$ 7. Steady-state fluorescence showed quenching fluorescence emission. BSA's binding with L was mainly due to hydrogen bonding, polar interactions, and hydrophobic interaction. Fluorescence anisotropy and lifetime experiments studies have clearly confirmed the binding of the ligand with BSA. Further, the molecular docking analysis confirmed the interaction between BSA and ligand.

\section{Funding}

Dr. Jali acknowledges a fund from DST, India, by EMEQ project (No.-EEQ/2019/000091). The authors also thank the Department of Chemistry, VSSUT, Burla for providing a research facility.

\section{Acknowledgments}

Dr. Jali thank the Department of Chemistry, VSSUT, Burla for providing a research facility.

\section{Conflicts of Interest}

The authors have declared that no competing interests exist.

\section{References}

1. Royer, C.A. Probing Protein Folding and Conformational Transitions with Fluorescence. Chem. Rev. 2006, 106, 1769-1784, https://doi.org/10.1021/cr0404390.

2. Cohen, B.E.; McAnaney, T.B.; Park, E.S.; Jan, Y.N.; Boxer, S.G.; Jan, L.Y. Probing Protein Electrostatics with a Synthetic Fluorescent Amino Acid. Science 2002, 296, 1700, https://doi.org/10.1126/science.1069346.

3. Abou-Zied, O.K.; Al-Shihi, O.I.K. Characterization of Subdomain IIA Binding Site of Human Serum Albumin in its Native, Unfolded, and Refolded States Using Small Molecular Probes. J. Am. Chem. Soc. 2008, 130, 10793-10801, https://doi.org/10.1021/ja8031289.

4. Er, J.C.; Vendrell, M.; Tang, M.K.; Zhai, D.; Chang, Y.-T. Fluorescent Dye Cocktail for Multiplex Drug-Site Mapping on Human Serum Albumin. ACS Combinatorial Science 2013, 15, 452-457, https://doi.org/10.1021/co400060b.

5. Jali, B.R.; Kuang, Y.; Neamati, N.; Baruah, J.B. Selective binding of naphthoquinone derivatives to serum albumin proteins and their effects on cytotoxicity. Chem.-Biol. Interact. 2014, 214, 10-17, https://doi.org/10.1016/j.cbi.2014.01.014.

6. Behera, S.; Behura, R.; Mohanty, M.; Dinda, R.; Mohanty, P.; Verma, A.K.; Sahoo, S.K.; Jali, B.R. Spectroscopic, cytotoxicity and molecular docking studies on the interaction between 2,4dinitrophenylhydrazine derived Schiff bases with bovine serum albumin. Sensors International 2020, 1, 100048, https://doi.org/10.1016/j.sintl.2020.100048. 
7. Gupta, A.; Patel, V.K.; Pandey, C. Functional Characterization of Nano-Porous Silicate-Polymer Composite for Bovine Serum Albumin Immobilization. Sensors International 2021, 100080, https://doi.org/10.1016/j.sintl.2021.100080.

8. Yu, Y.; Gong, Q.-T.; Lu, W.-F.; Liu, Y.-H.; Yang, Z.-J.; Wang, N.; Yu, X.-Q. Aggregation-Induced Emission Probes for Specific Turn-On Quantification of Bovine Serum Albumin. ACS Applied Bio Materials 2020, 3 , 5193-5201, https://doi.org/10.1021/acsabm.0c00589.

9. De Rosa, C.; Melchior, A.; Sanadar, M.; Tolazzi, M.; Giorgetti, A.; Ribeiro, R.P.; Nardon, C.; Piccinelli, F. Effect of the Heteroaromatic Antenna on the Binding of Chiral Eu(III) Complexes to Bovine Serum Albumin. Inorg. Chem. 2020, 59, 12564-12577, https://doi.org/10.1021/acs.inorgchem.0c01663.

10. Kelley, D.; McClements, D.J. Interactions of bovine serum albumin with ionic surfactants in aqueous solutions. Food Hydrocolloids 2003, 17, 73-85, https://doi.org/10.1016/S0268-005X(02)00040-1.

11. Chakraborty, A.; Seth, D.; Setua, P.; Sarkar, N. Photoinduced Electron Transfer in a Protein-Surfactant Complex: Probing the Interaction of SDS with BSA. The Journal of Physical Chemistry B 2006, 110, 1660716617, https://doi.org/10.1021/jp0615860.

12. Bhattacharya, B.; Nakka, S.; Guruprasad, L.; Samanta, A. Interaction of Bovine Serum Albumin with Dipolar Molecules: Fluorescence and Molecular Docking Studies. The Journal of Physical Chemistry B 2009, 113, 2143-2150, https://doi.org/10.1021/jp808611b.

13. Sasmal, M.; Bhowmick, R.; Musha Islam, A.S.; Bhuiya, S.; Das, S.; Ali, M. Domain-Specific Association of a Phenanthrene-Pyrene-Based Synthetic Fluorescent Probe with Bovine Serum Albumin: Spectroscopic and Molecular Docking Analysis. ACS Omega 2018, 3, 6293-6304, https://doi.org/10.1021/acsomega.8b00186.

14. Islam, M.M.; Barik, S.; Sarkar, M. Probing the Interactions of 1-Alkyl-3-methylimidazolium Tetrafluoroborate (Alkyl = Octyl, Hexyl, Butyl, and Ethyl) Ionic Liquids with Bovine Serum Albumin: An Alkyl Chain Length-Dependent Study. The Journal of Physical Chemistry B 2019, 123, 1512-1526, https://doi.org/10.1021/acs.jpcb.8b10795.

15. Karmakar, S.; Das, T.K.; Kundu, S.; Maiti, S.; Saha, A. Physicochemical Understanding of Protein-Bound Quantum Dot-Based Sensitive Probing of Bilirubin: Validation with Real Samples and Implications of Protein Conformation in Sensing. ACS Applied Bio Materials 2020, 3, 8820-8829, https://doi.org/10.1021/acsabm.0c01165.

16. Ma, G.J.; Ferhan, A.R.; Jackman, J.A.; Cho, N.-J. Elucidating How Different Amphipathic Stabilizers Affect BSA Protein Conformational Properties and Adsorption Behavior. Langmuir 2020, 36, 10606-10614, https://doi.org/10.1021/acs.langmuir.0c02048.

17. Haldar, B.; Chakrabarty, A.; Mallick, A.; Mandal, M.C.; Das, P.; Chattopadhyay, N. Fluorometric and Isothermal Titration Calorimetric Studies on Binding Interaction of a Telechelic Polymer with Sodium Alkyl Sulfates of Varying Chain Length. Langmuir 2006, 22, 3514-3520, https://doi.org/10.1021/la053370f.

18. Singh, N.; Kumar, N.; Rathee, G.; Sood, D.; Singh, A.; Tomar, V.; Dass, S.K.; Chandra, R. Privileged Scaffold Chalcone: Synthesis, Characterization and Its Mechanistic Interaction Studies with BSA Employing Spectroscopic and Chemoinformatics Approaches. ACS Omega 2020, 5, 2267-2279, https://doi.org/10.1021/acsomega.9b03479.

19. Barreleiro, P.C.A.; Lindman, B. The Kinetics of DNA-Cationic Vesicle Complex Formation. The Journal of Physical Chemistry B 2003, 107, 6208-6213, https://doi.org/10.1021/jp0277107.

20. Ghosh, S.; Jana, S.; Nath, D.; Guchhait, N. Fluorescent Probing of Protein Bovine Serum Albumin Stability and Denaturation Using Polarity Sensitive Spectral Response of a Charge Transfer Probe. Journal of Fluorescence 2011, 21, 365-374, https://doi.org/10.1007/s10895-010-0725-y.

21. Bharmoria, P.; Rao, K.S.; Trivedi, T.J.; Kumar, A. Biamphiphilic Ionic Liquid Induced Folding Alterations in the Structure of Bovine Serum Albumin in Aqueous Medium. The Journal of Physical Chemistry B 2014, 118, 115-124, https://doi.org/10.1021/jp4102042.

22. Dixon, J.M.; Egusa, S. Conformational Change-Induced Fluorescence of Bovine Serum Albumin-Gold Complexes. J. Am. Chem. Soc. 2018, 140, 2265-2271, https://doi.org/10.1021/jacs.7b11712.

23. Awasthi, S.; Murugan, N.A.; Saraswathi, N.T. Advanced Glycation End Products Modulate Structure and Drug Binding Properties of Albumin. Mol. Pharm. 2015, 12, 3312-3322, https://doi.org/10.1021/acs.molpharmaceut.5b00318.

24. Hu, Y.-J.; Liu, Y.; Wang, J.-B.; Xiao, X.-H.; Qu, S.-S. Study of the interaction between monoammonium glycyrrhizinate and bovine serum albumin. J. Pharm. Biomed. Anal. 2004, 36, 915-919, https://doi.org/10.1016/j.jpba.2004.08.021. 
25. Cui, F.-L.; Yan, Y.-H.; Zhang, Q.-Z.; Qu, G.-R.; Du, J.; Yao, X.-J. A study on the interaction between 5Methyluridine and human serum albumin using fluorescence quenching method and molecular modeling. $J$. Mol. Model. 2010, 16, 255-262, https://doi.org/10.1007/s00894-009-0548-4.

26. Bogdan, M.; Pirnau, A.; Floare, C.; Bugeac, C. Binding interaction of indomethacin with human serum albumin. J. Pharm. Biomed. Anal. 2008, 47, 981-984, https://doi.org/10.1016/j.jpba.2008.04.003.

27. Ibrahim, N.; Ibrahim, H.; Kim, S.; Nallet, J.-P.; Nepveu, F. Interactions between Antimalarial Indolone-Noxide Derivatives and Human Serum Albumin. Biomacromolecules 2010, 11, 3341-3351, https://doi.org/10.1021/bm100814n.

28. Martí, A.A.; Jockusch, S.; Stevens, N.; Ju, J.; Turro, N.J. Fluorescent Hybridization Probes for Sensitive and Selective DNA and RNA Detection. Acc. Chem. Res. 2007, 40, 402-409, https://doi.org/10.1021/ar600013q.

29. Wang, X.; Chen, S.; Zhao, C.; Long, L.; Wang, Y. Preparation of Dolutegravir Intermediate Diastereomer. J. Heterocycl. Chem. 2019, 56, 2063-2067, https://doi.org/10.1002/jhet.3588.

30. Morris, G.M.; Goodsell, D.S.; Halliday, R.S.; Huey, R.; Hart, W.E.; Belew, R.K.; Olson, A.J. Automated docking using a Lamarckian genetic algorithm and an empirical binding free energy function. J. Comput. Chem. 1998, 19, 1639-1662, https://doi.org/10.1021/acs.inorgchem.0c01663.

31. Trott, O.; Olson, A.J. AutoDock Vina: Improving the speed and accuracy of docking with a new scoring function, efficient optimization, and multithreading. J. Comput. Chem. 2010, 31, 455-461, https://doi.org/10.1002/jcc.21334.

32. Takeda, K.; Hachiya, K.; Moriyama, Y. Interaction of Protein with Ionic Surfactants: Part 2. Marcel Dekker: New York: 2002.

33. Li, X.-F.; Yang, Y.-Q.; Li, Y.-X.; Yang, H.-X.; Zhao, W.-F.; Meng, X.-R. Synthesis, crystal structure, and BSA binding studies of new $\mathrm{Co}(\mathrm{II})$ and $\mathrm{Ni}(\mathrm{II})$ complexes of 2-(hydroxymethyl)-1H-imidazole-4,5dicarboxylate. Inorg. Chim. Acta 2020, 505, 119469, https://doi.org/10.1016/j.ica.2020.119469.

34. Jena, B.B.; Satish, L.; Mahanta, C.S.; Swain, B.R.; Sahoo, H.; Dash, B.P.; Satapathy, R. Interaction of carborane-appended trimer with bovine serum albumin: A spectroscopic investigation. Inorg. Chim. Acta 2019, 491, 52-58, https://doi.org/10.1016/j.ica.2019.03.035.

35. Sun, C.; Yang, J.; Wu, X.; Huang, X.; Wang, F.; Liu, S. Unfolding and refolding of bovine serum albumin induced by cetylpyridinium bromide. Biophys. J. 2005, 88, 3518-3524, https://doi.org/10.1529/biophysj.104.051516.

36. Gensch, T.; Hendriks, J.; Hellingwerf, K.J. Tryptophan fluorescence monitors structural changes accompanying signalling state formation in the photocycle of photoactive yellow protein. Photochemical \& Photobiological Sciences 2004, 3, 531-536, https://doi.org/10.1039/B401600A.

37. Gentili, P.L.; Ortica, F.; Favaro, G. Static and Dynamic Interaction of a Naturally Occurring Photochromic Molecule with Bovine Serum Albumin Studied by UV-Visible Absorption and Fluorescence Spectroscopy. The Journal of Physical Chemistry B 2008, 112, 16793-16801, https://doi.org/10.1021/jp805922g.

38. Aneesrahman, K.N.; Ramaiah, K.; Rohini, G.; Stefy, G.P.; Bhuvanesh, N.S.P.; Sreekanth, A. Synthesis and characterisations of copper(II) complexes of 5-methoxyisatin thiosemicarbazones: Effect of N-terminal substitution on DNA/protein binding and biological activities. Inorg. Chim. Acta 2019, 492, 131-141, https://doi.org/10.1016/j.ica.2019.04.019.

39. Burstein, E.A.; Vedenkina, N.S.; Ivkova, M.N. Fluorescence and the location of tryptophan residues in protein molecules. Photochem. Photobiol. 1973, 18, 263-279, https://doi.org/10.1111/j.17511097.1973.tb06422.x.

40. Ojha, B.; Das, G. The Interaction of 5-(Alkoxy)naphthalen-1-amine with Bovine Serum Albumin and Its Effect on the Conformation of Protein. The Journal of Physical Chemistry B 2010, 114, 3979-3986, https://doi.org/10.1021/jp907576r.

41. González Flecha, F.L.; Levi, V. Determination of the molecular size of BSA by fluorescence anisotropy. Biochem. Mol. Biol. Educ. 2003, 31, 319-322, https://doi.org/10.1002/bmb.2003.494031050261.

42. Carter, D.C.; Ho, J.X. Structure of Serum Albumin. In Adv. Protein Chem., Anfinsen, C.B., Edsall, J.T., Richards, F.M., Eisenberg, D.S., Eds. Academic Press: 1994; Vol. 45, 153-203, https://doi.org/10.1016/S0065-3233(08)60640-3.

43. Chaves, O.A.; da Silva, V.A.; Sant'Anna, C.M.R.; Ferreira, A.B.B.; Ribeiro, T.A.N.; de Carvalho, M.G.; Cesarin-Sobrinho, D.; Netto-Ferreira, J.C. Binding studies of lophirone B with bovine serum albumin (BSA): Combination of spectroscopic and molecular docking techniques. J. Mol. Struct. 2017, 1128, 606-611, https://doi.org/10.1016/j.molstruc.2016.09.036. 
44. Teng, Y.; Zou, L.; Huang, M.; Zong, W. Characterization of the binding of 2-mercaptobenzimidazole to bovine serum albumin. J. Mol. Recognit. 2015, 28, 232-238, https://doi.org/10.1002/jmr.2437.

45. Zhang, Y.; Li, Y.; Dong, L.; Li, J.; He, W.; Chen, X.; Hu, Z. Investigation of the interaction between naringin and human serum albumin. J. Mol. Struct. 2008, 875, 1-8, https://doi.org/10.1016/j.molstruc.2007.03.063.

46. Amiri, M.; Jankeje, K.; Albani, J.R. Characterization of human serum albumin forms with pH. Fluorescence lifetime studies. J. Pharm. Biomed. Anal. 2010, 51, 1097-1102, https://doi.org/10.1016/j.jpba.2009.11.011.

47. Pace, C.N.; Vajdos, F.; Fee, L.; Grimsley, G.; Gray, T. How to measure and predict the molar absorption coefficient of a protein. Protein Sci. 1995, 4, 2411-2423, https://doi.org/10.1002/pro.5560041120.

48. Helms, M.K.; Petersen, C.E.; Bhagavan, N.V.; Jameson, D.M. Time-resolved fluorescence studies on sitedirected mutants of human serum albumin. FEBS Lett. 1997, 408, 67-70, https://doi.org/10.1016/S00145793(97)00389-X.

49. Davis, D.M.; McLoskey, D.; Birch, D.J.S.; Gellert, P.R.; Kittlety, R.S.; Swart, R.M. The fluorescence and circular dichroism of proteins in reverse micelles: application to the photophysics of human serum albumin and N-acetyl-1-tryptophanamide. Biophys. Chem. 1996, 60, 63-77, https://doi.org/10.1016/03014622(96)00016-6.

50. Marzola, P.; Gratton, E. Hydration and protein dynamics: frequency domain fluorescence spectroscopy of proteins in reverse micelles. The Journal of Physical Chemistry 1991, 95, 9488-9495, https://doi.org/10.00223654/91/2095-9488S02.50/0.

51. René Albani, J. Fluorescence Lifetimes of Tryptophan: Structural Origin and Relation with So $\rightarrow$ 1Lb and So $\rightarrow$ 1La Transitions. Journal of Fluorescence 2009, 19, 1061, https://doi.org/10.1007/s10895-009-0506-7.

52. Tayeh, N.; Rungassamy, T.; Albani, J.R. Fluorescence spectral resolution of tryptophan residues in bovine and human serum albumins. J. Pharm. Biomed. Anal. 2009, 50, 107-116, https://doi.org/10.1016/j.jpba.2009.03.015.

53. Patel, A.B.; Srivastava, S.; Phadke, R.S. Interaction of 7-Hydroxy-8-(phenylazo) 1, 3-naphthalenedisulfonate with Bovine Plasma Albumin SPECTROSCOPIC STUDIES. J. Biol. Chem. 1999, 274, 21755-21762, https://doi.org/10.1074/jbc.274.31.21755.

54. Cui, F.-L.; Fan, J.; Li, J.-P.; Hu, Z.-D. Interactions between 1-benzoyl-4-p-chlorophenyl thiosemicarbazide and serum albumin: investigation by fluorescence spectroscopy. Biorg. Med. Chem. 2004, 12, 151-157, https://doi.org/10.1016/j.bmc.2003.10.018.

55. Jali, B.R.; Behura, R.; Barik, S.R.; Parveen, S.; Mohanty, S.P.; Das, R. A Brief Review: Biological Implications of Naphthoquinone Derivatives. Research Journal of Pharmacy and Technology 2018, 11, 36983702, https://doi.org/10.5958/0974-360X.2018.00679.0.

56. Lin, N.; Ren, W.; Hu, J.; Gao, B.; Yuan, D.; Wang, X.; Fu, J. A novel tetraphenylethene-based fluorescent sensor for uranyl ion detection with aggregation-induced emission character. Dyes and Pigments 2019, 166, 182-188, https://doi.org/10.1016/j.dyepig.2019.02.048.

57. Liu, Z.-m.; Du, H.-j.; Wang, T.-q.; Ma, Y.-n.; Liu, J.-r.; Yan, M.-c.; Wang, H.-y. Selective and sensitive detection and quantification of human carboxylesterase 1 by a ratiometric fluorescence probe. Dyes and Pigments 2019, 171, 107711, https://doi.org/10.1016/j.dyepig.2019.107711.

58. Karami, K.; Jamshidian, N.; Bagheri, A.; Hajiaghasi, A.; Momtazi-Borojeni, A. A.; Abdollahi, E.; Shahpiri, A.; Azizi, N.; Lipkowski, J. Novel fluorescence palladium-alkoxime complexes: Synthesis, characterization, DNA/BSA spectroscopic and docking studies, evaluation of cytotoxicity and DNA cleavage mechanism. $J$. Mol. Struct. 2020, 1206, 127595. https://doi.org/10.1016/j.molstruc.2019.127595.

59. Kataria, R.; Vashisht, D.; Sindhu, J.; Sharma, S.; Mehta, S. K.; Kumar, R.; Sahoo, S. C.; Kumar, S.; Qu, F.; Afkhami, F. A.; Gupta, A. Crystal structure, Hirshfeld surface, DFT and BSA binding studies of dihydropyrazole-1-thiocarboxamides. J. Mol. Struct. $\quad$ 2019, $\quad$ 1196, $662-675$. https://doi.org/10.1016/j.molstruc.2019.06.100.

60. Benesi, H.A.; Hildebrand, J.H. A Spectrophotometric Investigation of the Interaction of Iodine with Aromatic Hydrocarbons. J. Am. Chem. Soc. 1949, 71, 2703-2707, https://doi.org/10.1021/ja01176a030. 